\title{
Psychological Contract Violation and Sharing Intention on Facebook
}

\author{
Bryan Hammer \\ Oklahoma State \\ University \\ bryan.hammer@oksta \\ te.edu
}

\author{
Tianjian Zhang \\ Oklahoma State \\ University \\ tj.zhang@okstate.edu
}

\author{
Forough Nasirpouri \\ Shadbad \\ Oklahoma State \\ University \\ nasirpo@okstate.edu
}

\author{
Rupesh Agrawal \\ Oklahoma State \\ University \\ rupesh.agrawal@okst \\ ate.edu
}

\begin{abstract}
While there is a psychological component to every written contract, it is particularly the case for exchanges on social network site (SNS), where users tend to ignore the user agreement. As a form of social exchange, content sharing on SNS is guided by psychological contract, i.e., implicit and assumed reciprocal obligations. This study investigates how psychological contract violations (PCVs) affect people's sharing intentions on Facebook. Based on a survey of 347 Facebook users, we find that sharing intention is negatively influenced by interpersonal and institutional PCVS through SNS users' information privacy concern and trust. Interestingly, $P C V$ by another user positively influences the affected user's perceived violation by the SNS, suggesting a collateral damage of interpersonal PCV towards SNS. This paper adds to the privacy literature on SNS by revealing the fundamental role of PCV that alters users' trust and information privacy concern in online social exchange.
\end{abstract}

\section{Introduction}

Social media is all about sharing and interaction [1]. As in any social exchange, content sharing on social network sites (SNS) is governed by social norms and contracts. The only explicit contract for SNS is the user agreement, which ironically users rarely read [2]. Conceivably, the psychological component of the user agreement plays a significant role in users' behavioral intention on SNS. In a social exchange between two parties, a psychological contract is formed when one party assumes certain beliefs about reciprocal obligations with the other party [3]. Since psychological contract violation (PCV) is detrimental towards organizational and individual relationships [4-6], this study examines the effect of PCVs towards users' sharing intentions on SNS.

One of the central questions of interest in online social exchange is the mechanisms that affect people's willingness to compromise a certain level of privacy in exchange for goods or services [7-10]. These studies typically involve privacy concern $[11,12]$ and trust $[13-$ 15]. The overlapping dimension of the two constructs is expectation, which is embedded in the conceptualization of a psychological contract. While trust embodies the expectation that another party will not engage in opportunistic behavior [9], information privacy concern represents users' expectations of how their privacy should be protected [10]. As different parties' expectations do not necessarily coincide, the asymmetry in expectation gives rise to psychological contract violation (PCV). While PCV has been applied in e-commerce [4, 8, 16-18] and IT-outsourcing [19, 20], its impacts in the hedonic context (SNS) is understudied. To bridge this gap, this study investigates: a) how a user's sharing intention on SNS is affected by psychological contract violation of another user (RQ1); b) how a user's sharing intention on SNS is affected by psychological contract violation of the SNS (RQ2).

Guided by organizational behavior literature on psychological contracts and information systems literature concerning privacy on social media, this study considers PCV as the fundamental construct that affects SNS users' information privacy concerns and trust, which, in turn, determine users' sharing intentions. Psychological contracts are broader than legal contracts since they include implicit terms beyond written statements. While PCV is traditionally examined for employee versus organization relationships, the context has also been extended to interpersonal relationships in e-commerce [4]. This study extends the literature further by investigating both interpersonal and institutional PCVs on SNS.

In this paper, we utilized 347 survey observations collected from Amazon Mechanical Turk (MTurk) to study the effect of PCV on Facebook users' sharing intention. We chose MTurk since US samples from MTurk have been shown to create similar statistical conclusions as U.S. students and U.S. consumer panels [21]. Facebook is used as the focal SNS since it is the largest platform by the number of active users [22]. All construct measures are adapted from the literature, albeit in different contexts in some cases. The results indicate a significant negative effect of PCV towards 
sharing intention on Facebook through information privacy concern or trust.

This study extends the PCV literature to SNS context, and contributes to the privacy literature by providing evidence on how interpersonal and institutional PCVs disrupt users' sharing intention. Theoretically, the paper suggests that psychological contract is fundamental in determining users' sharing intention by altering their trust and privacy concerns. The "spillover" effect from interpersonal PCV towards institutional PCV points to users' irrational generalizations of violations to unrelated parties. For practitioners, this study will shed light on how institutional privacy violations affect users' sharing intention on SNS. The rest of the article is organized as follows. We review the relevant psychological contract and privacy literature, and develop hypotheses in $\$ 2$. Data collection and analyses are presented in $\S 3$. Finally, we discuss the limitations and implications of this study in $\S 4$.

\section{Theoretical development}

\subsection{Psychological contract violation}

A psychological contract is an individual's beliefs regarding the terms and conditions of a reciprocal exchange agreement between the individual and another party [3, 23]. Unlike contracts on paper where two parties reach an agreement, a psychological contract is one person's belief regarding the reciprocal relationship, which is perceptual, unwritten, and implicit [3, 23, 24]. Since no contract can be perfectly complete [25], there is a psychological component in all contracts, where a party to the agreement will assume certain obligations from the other party and vice versa.

A psychological contract violation $(P C V)$ occurs when one party perceives that the other party has failed to fulfill its obligations or promises [26]. Notably, PCV can occur when there is merely a perception of violation, where the underlying social or written contract may or may not have been breached. Organizational behavior literature has extensively examined how PCV influences employment relationships [3, 6, 27, 28]. When an employee believes that the organization failed to fulfil one or more obligations or promises, he or she will develop feelings of anger and betrayal towards the organization [27]. While Robinson and Morrison [6] distinguishes between psychological contract violation (feeling) and psychological contract breach (perception), we follow the original unitary conceptualization by Rousseau [3] as in Pavlou and Gefen [4].
It has been shown that PCV is prevalent among employment relationships [28]. We argue that PCV is also ubiquitous and is a suitable construct for both interpersonal relationships on SNSs and relationships between individuals and SNSs. For interpersonal interactions, online communications typically cannot convey individuals' expectations towards the other party through facial expressions or tone of speeches. The lack of face-to-face communications on SNS will likely incur more discrepancies in assumptions about reciprocal obligations among users, thus inducing a bigger role for interpersonal PCVs. PCV is also prevalent and likely more severe for relationships between individuals and SNSs, since most users will not read the 3400 words terms of service on Facebook [29], and there is no explicit contract among users. The recent infamous Cambridge Analytica incident revealed that Facebook failed to protect 87 million users' data from being inappropriately extracted to aid political campaigns [30]. The massive psychological contract violations have led to the subsequent \#DeleteFacebook movement.

While PCV has not been explicitly applied in the context of SNS to the best of our knowledge, Choi et al. [31] revealed that embarrassing exposures in SNS will affect perceived privacy invasion and subsequent behaviors. These exposures, such as getting tagged in a Facebook post for sleeping in a lecture [31], can be perceived as a violation of the interpersonal psychological contract. Studies in other subfields of IS have more explicit applications of PCV. For examples, the effect of PCV has been investigated for buyerseller(s) relationships in e-commerce [4, 8, 16-18] and interorganizational relationships in IT-outsourcing [19, 20]. In particular, PCV has been used to examine relationships between individual buyers and sellers [4], thus extending PCV with an institution to PCV with individuals. Following the definition in Pavlou and Gefen [4], interpersonal PCV is defined here as an individual user's beliefs of having been treated wrongly by another user on the SNS; Institutional PCV is defined here as the user's overall perception that the SNS has generally failed to fulfill its contractual obligations.

Interestingly, interpersonal PCV may have a spillover effect towards institutional PCV, since emotions and attitudes triggered by violation with one party may be generalized to unrelated parties [32, 33]. For an online setting, PCV by one online seller has been found to positively influence PCV by a community of sellers [4]. Therefore, we posit that individual users may project discontent due to PCV with another user towards the SNS. 
H1: Interpersonal psychological contract violations on a social network site will have a positive effect on institutional psychological contract violations.

\subsection{Privacy concern, trust, sharing intention}

Individuals' sharing intention on SNS has been shown to be related to their trust and privacy concerns $[11,12,15]$, both of which have been extensively applied in studies for social media and other contexts. Information privacy concerns are an individual's subjective views of fairness within the context of information privacy [34]. The concept has been extended to fit the online context. Malhotra et al. [10] conceptualized a second order construct, Internet users' information privacy concern (IUIPC), as "the degree to which an Internet user is concerned about online marketers' collection of personal information, the user's control over the collected information, and the user's awareness of how the collected information is used".

While IUIPC was initially developed for ecommerce settings, it was first applied to study behavioral intention of releasing personal information [10]. Although SNS users may share publicly available information (e.g., news stories), such sharing still reveals personal information to some extent. For instance, even sharing a neutral news story may reveal users' sharing location, reading habits, or the basic fact that the user is interested in the story. Hence, IUIPC is suitable for the social network context of this study.

Psychological contracts and IUIPC are linked by social contract, which refers to the assumptions, beliefs, and norms about appropriate behavior within a particular social unit [35]. On one hand, social contract governs the execution of the psychological contract, indicating how the reciprocal exchange in a psychological contract should be carried out [27]. Thus, it serves as a backdrop for individuals' interpretation of contract violation [27]. On the other hand, the three pillars of IUIPC, collection, control, and awareness, are also derived from social contract theory. Collection emphasizes equitable information exchange based on the agreed social contract; control represents the freedom to voice an opinion or exit; and awareness indicates understanding about established conditions in the social contract and actual practices [10]. Consequently, when a psychological contract is violated by an SNS, the user has made the judgement that the SNS has violated the agreed social contract, which will raise the level of information privacy concern. Since IUIPC is users' concern towards an online company, we do not expect a direct relationship between interpersonal
PCV and IUIPC. Therefore, we posit that only institutional PCV positively influences IUIPC.

H2: Institutional psychological contract violation with a social network site will have a positive effect on users' information privacy concern of the site.

The role of trust in online exchange is wellestablished, and has been extensively applied in both ecommerce [17, 36-39] and social media [11, 13-15]. Trust is the belief that the trustee will fulfill the trustor's expectations without taking advantage of its vulnerabilities [40, 41]. As in PCV, trust can be divided into interpersonal and institutional. Interpersonal trust on SNS is trust between individual users [14, 42]. Institutional trust is the user's perception that effective mechanisms are in place to assure that the SNS service will behave consistently with the user's favorable expectations [14, 43].

Trust is closely related to the psychological contract. PCV is typically accompanied with feelings of anger and betrayal, which will reduce the trustor's belief in the trustee. Organizational behavior literature found that PCV decreases employees' trust towards their employers [5, 28, 44]. When violations occur, the trustee has failed to fulfill certain obligations in the eyes of the trustor, hence subsequent trust will diminish. Ecommerce literature also found a negative relationship between PCV and trust [4]. Hence, we expect similar relationships between PCV and trust under the SNS setting.

H3: Interpersonal psychological contract violation with an individual user on a social network site will have a negative effect on interpersonal trust in the user.

H4: Institutional psychological contract violation with a social network site will have a negative effect on institutional trust in the site.

The negative relationship between Internet users' information privacy concern and institutional trust is also well-documented [8, 10, 12]. When a user has concerns over control, collection, or awareness as defined in IUIPC, he or she will perceive that the SNS is more likely to take advantage of the vulnerabilities, hence reducing users' trust towards the SNS. Since IUIPC is users' concern towards the SNS, we posit that IUIPC only affects institutional trust.

H5: A social network user's information privacy concern will have a negative effect 
on the user's institutional trust towards the social network site.

Finally, sharing intention is defined as the intention to reveal information on an SNS [10, 45]. There is a well-established positive relationship between trust and behavioral intention in online exchange $[4,9,10,14,16$, 46]. When the trustor expects the trustee to fulfill the trustor's expectation and feels less likely to be taken advantage of, he or she will be more likely to disclose information to the trustee. Hence, we posit the followings.

H6: A social network user's interpersonal trust will have a positive effect on his/her sharing intention on the social network site.

H7: A social network user's institutional trust will have a positive effect on his/her sharing intention on the social network site.

The hypotheses are illustrated in figure 1.

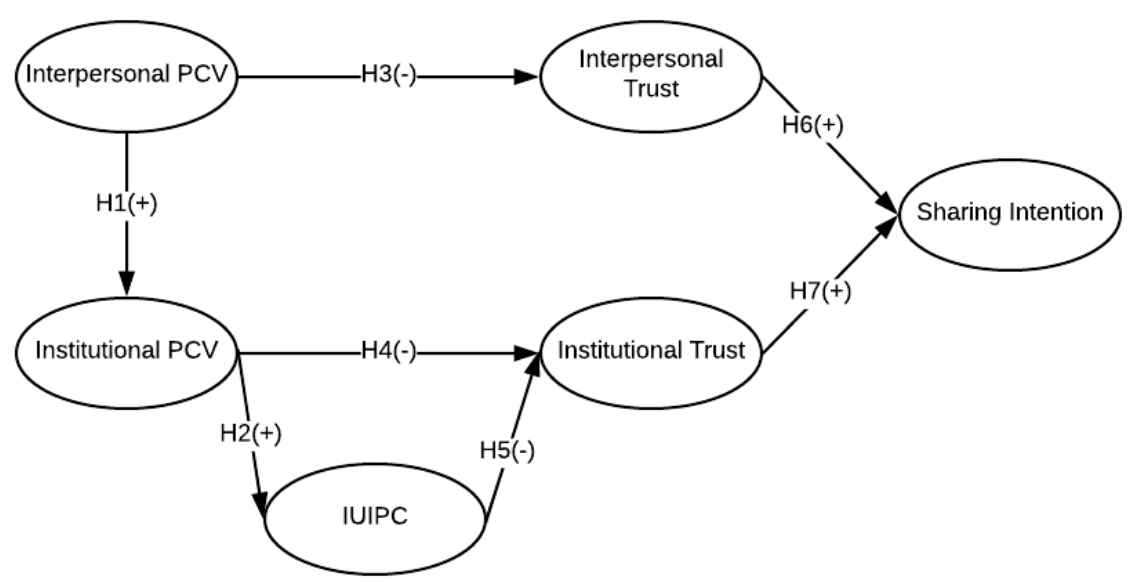

Figure1. Hypothesized model of information sharing intention on SNS

\section{Methodology}

\subsection{Measurement development and survey administration}

Facebook was chosen as the underlying platform because it is the largest SNS in terms of the number of users [22, 47]. Measurement items (Table 1) were adapted from the literature to fit the Facebook context. Items for institutional PCV were based on Robinson and
Morrison [6]. Interpersonal PCV items were similar to that in Pavlou and Gefen [4]. Following Malhotra, et al. [10], IUIPC was measured through three first-order latent variables: collection, awareness, and control. The items for institutional trust were based on Sledgianowski and Kulviwat [14], which are tailormade for the SNS context. Interpersonal trust follows Gefen, et al. [46]. Finally, sharing intention was measured by adapted items from Lee and Ma [45]. All items used 7-point Likert scale (Strongly disagree... Strongly agree).

Table1. Measurement Items and Loadings

\begin{tabular}{ccc}
\hline Latent Variable & Reflective Measures & Loading \\
\hline $\begin{array}{c}\text { Interpersonal } \\
\text { PCV [6] }\end{array}$ & PCVITP 1. I have experienced a significant disagreement with a specific user on & Facebook. \\
& PCVITP 2. I have experienced a significant problem with a specific user on Facebook. & 0.71 \\
& PCVITP 3. I have experienced a significant violation of unspoken agreement with a specific & 0.93 \\
user on Facebook. & 0.89 \\
\hline & PCVIST 1. I feel a great deal of anger toward Facebook. & 0.92 \\
Institutional & PCVIST 2. I feel betrayed by Facebook. & 0.89 \\
PCV [4] & PCVIST 3. I feel that Facebook has violated the user agreement between us. & \\
\hline
\end{tabular}




\begin{tabular}{|c|c|c|}
\hline & CVIST 4. I feel extremely frustrated by how I have been treated by Facebook. & 0.94 \\
\hline \multirow{3}{*}{$\begin{array}{l}\text { IUIPC - Control } \\
{[10]}\end{array}$} & $\begin{array}{l}\text { CTL 1. Facebook users' privacy is the right to exercise control and autonomy regarding } \\
\text { how user information is collected, used, and shared. }\end{array}$ & 0.69 \\
\hline & CTL 2. Facebook users' control of personal information lies at the heart of user privacy. & 0.86 \\
\hline & $\begin{array}{l}\text { CTL3. Facebook users' privacy is invaded when control is reduced as a result of a } \\
\text { Facebook advertisement. }\end{array}$ & 0.66 \\
\hline \multirow{3}{*}{$\begin{array}{c}\text { IUIPC - } \\
\text { Awareness } \\
{[10]}\end{array}$} & AWE 1. Facebook should disclose the way the data are collected, processed, and used. & 0.84 \\
\hline & AWE 2. Facebook's privacy policy should have a clear and conspicuous disclosure. & 0.92 \\
\hline & $\begin{array}{l}\text { AWE 3. It is very important to me that I am aware and knowledgeable about how my } \\
\text { personal information will be used. }\end{array}$ & 0.70 \\
\hline \multirow{4}{*}{$\begin{array}{l}\text { IUIPC - } \\
\text { Collection [10] }\end{array}$} & CLC 1. It usually bothers me when Facebook asks me for personal information. & 0.79 \\
\hline & $\begin{array}{l}\text { CLC 2. When Facebook asks me for personal information, I sometimes think twice before } \\
\text { providing it. }\end{array}$ & Dropped \\
\hline & CLC 3. It bothers me to give personal information to so many social networks. & 0.85 \\
\hline & $\begin{array}{l}\text { CLC 4. I'm concerned that that Facebook is collecting too much personal information about } \\
\text { me. }\end{array}$ & 0.83 \\
\hline \multirow{7}{*}{$\begin{array}{l}\text { Interpersonal } \\
\text { Trust [46] }\end{array}$} & $\begin{array}{l}\text { TSTITP 1. Based on what my friends have posted on Facebook, I know he/she is not } \\
\text { opportunistic. }\end{array}$ & Dropped \\
\hline & $\begin{array}{l}\text { TSTITP 2. Based on what my friends have posted on Facebook, I know he/she is honest. } \\
\text { TSTITP } 3 \text {. Based on what my friends have posted on Facebook, I know he/she cares }\end{array}$ & 0.85 \\
\hline & about his/her Facebook friends. & 0.87 \\
\hline & TSTITP 4. Based on what my friends have posted on Facebook, I know he/she is reliable. & 0.90 \\
\hline & $\begin{array}{l}\text { TSTITP 5. Based on what my friends have posted on Facebook, I know he/she is } \\
\text { predictable. }\end{array}$ & 0.72 \\
\hline & $\begin{array}{l}\text { TSTITP 6. Based on what my friends have posted on Facebook, I know he/she is } \\
\text { trustworthy. }\end{array}$ & Dropped \\
\hline & $\begin{array}{l}\text { TSTITP 7. Based on what my friends have posted on Facebook, I know he/she knows } \\
\text { his/her Facebook friends. }\end{array}$ & Dropped \\
\hline \multirow{5}{*}{$\begin{array}{l}\text { Institutional } \\
\text { Trust [14] }\end{array}$} & TSTIST 1. I feel that Facebook is honest. & Dropped \\
\hline & TSTIST 2. I feel that Facebook is responsible. & Dropped \\
\hline & TSTIST 3. I feel that Facebook understands its customers. & 0.76 \\
\hline & TSTIST 4. I feel that Facebook cares about me. & 0.75 \\
\hline & TSTIST 5. I feel that Facebook is very professional. & 0.88 \\
\hline Sharing & SHA 1. I intend to keep sharing in Facebook in the future. & 0.89 \\
\hline \multirow[t]{2}{*}{ Intention [45] } & SHA 2. I expect to share Facebook posts contributed by other users. & 0.80 \\
\hline & SHA 3. I plan to keep sharing in Facebook regularly. & 0.96 \\
\hline
\end{tabular}

To ensure that participants experience feelings of violation, they were asked to answer survey questions based on a randomly assigned vignette. Four vignettes (table 2) were developed through semi-structured interviews with reference to scenarios in Choi et al. [31]. Vignette 1 and 2 are for high/low violations due to another Facebook user, and Vignette 3 and 4 are for high/low violations due to Facebook. Participants of the survey were first asked to rate the severity of the assigned scenario. Unpaired $t$-tests (table 2) showed significant differences between high and low vignettes.

The survey was conducted among US individuals on Amazon Mechanical Turk (MTurk), which is known to produce similar statistical results as U.S. students and U.S. consumer panels [21]. Participation was voluntary, and each participant received a small monetary reward for providing a quality response. MTurk data has been shown to be of high quality even with relatively low cost [48]. The survey included three attention questions (e.g. "select strongly disagree") to ensure quality responses. Of all 456 participants, 449 individuals completed the survey. After removing questionable responses based on attention questions and time spent on the survey, the final sample size is 347 . The survey respondents' profile is given in Table 3. The demographic distribution reveals a diverse sample of individuals with different levels of education, employment, race, gender, and usage behavior on Facebook. 
Table 2. Vignettes for Psychological Contract Violation

\begin{tabular}{|c|c|c|c|c|}
\hline & Vignettes & Mean & SD & $t$-test $($ High $>$ Low $)$ \\
\hline $\begin{array}{l}\text { Vig 1: High } \\
\text { interpersonal PCV }\end{array}$ & $\begin{array}{l}\text { A colleague posted a drunk photo of you in your office } \\
\text { party on his/her Facebook without your consent. }\end{array}$ & 5.61 & 1.70 & \multirow{2}{*}{$p<0.001$} \\
\hline $\begin{array}{l}\text { Vig 2: Low } \\
\text { interpersonal PCV }\end{array}$ & $\begin{array}{l}\text { You were tagged in a fishing trip by a close friend on } \\
\text { Facebook without your consent. }\end{array}$ & 3.73 & 1.90 & \\
\hline $\begin{array}{l}\text { Vig 3: High } \\
\text { institutional PCV }\end{array}$ & $\begin{array}{l}\text { Your entire Facebook profile was unlawfully extracted to } \\
\text { aid a political campaign due to negligence of Facebook. }\end{array}$ & 6.06 & 1.48 & \multirow[b]{2}{*}{$p<0.01$} \\
\hline $\begin{array}{l}\text { Vig 4: Low } \\
\text { institutional PCV }\end{array}$ & $\begin{array}{l}\text { Your Facebook friend list was exposed to a gaming app } \\
\text { on Facebook due to hidden terms of Facebook. }\end{array}$ & 5.54 & 1.27 & \\
\hline
\end{tabular}

Table 3. Descriptive Statistics of Survey Respondents $(N=347)$

\begin{tabular}{|c|c|c|c|c|c|}
\hline \multicolumn{2}{|c|}{ Race } & \multicolumn{2}{|l|}{ Gender } & \multicolumn{2}{|c|}{ Age } \\
\hline White/Caucasian & $255(73.4 \%)$ & Male & $203(58.5 \%)$ & $<18$ years & $98(28.2 \%)$ \\
\hline African American & 35 (10.0\%) & Female & 144 (41.4\%) & $18-30$ years & 114 (32.8\%) \\
\hline Hispanic & $16(4 / 6 \%)$ & Other & 0 & $31-40$ years & $58(16.7 \%)$ \\
\hline Asian & $23(6.6 \%)$ & & & $41-50$ years & 42 (12.1\%) \\
\hline Native American & $9(2.5 \%)$ & & & $>60$ years & $35(10.0 \%)$ \\
\hline Pacific Islander & 0 & & & & \\
\hline Other & $8(2.3 \%)$ & & & & \\
\hline Do not want to disclose & $1(0.2 \%)$ & & & & \\
\hline Average time spending & Facebook daily & Wor & atus & Education & \\
\hline$<30$ mins & $79(22.7 \%)$ & Fulltime & $212(61.0 \%)$ & High School & 69 (19.8\%) \\
\hline $30-60$ mins & $115(33.1 \%)$ & Part-time & $65(18.7 \%)$ & College & $174(50.1 \%)$ \\
\hline $1-2 \mathrm{hrs}$ & $91(26.2 \%)$ & Unemployed & $70(20.1 \%)$ & Graduate & $101(29.1 \%)$ \\
\hline $2-4 \mathrm{hrs}$ & $45(12.9 \%)$ & & & Other & $3(.8 \%)$ \\
\hline$>4 \mathrm{hrs}$ & $17(4.8 \%)$ & & & & \\
\hline
\end{tabular}

\subsection{Measurement and Structural Models}

A measurement model was estimated before testing the hypotheses to avoid misinterpretation of structural relationships [49]. Following the two-step approach, we first assessed the quality of the measures through Confirmatory Factor Analysis (CFA), and in step two we tested the hypotheses by performing path analysis through Structural Equation Modeling (SEM). For the model assessment, maximum likelihood estimation was employed.

CFA was performed on each construct separately and then on the entire set of items simultaneously. In order to obtain a good model fit, we removed a total of six items from IUIPC, interpersonal trust and institutional trust (see table 1). These removed items showed low item loadings and high residuals covariance with other items. The finalized CFA suggests that the measurement model fits the data well (table 4).

Apart from the model fit, we examined the reliability, convergent and discriminant validity of the measurements. A scale is reliable if composite reliability (CR) is higher than 0.70 and average variance extracted (AVE) is greater than $0.50[50,51]$. Table 5 suggests that all items are reliable. Convergent validity was established since all item loadings (see table 1) were well above the recommended threshold of 0.60 [52]. Discriminant validity was verified as the square root of AVE (see table 5) of each construct is larger than the correlation coefficients shared between the construct and other constructs [51].

Table 4. Goodness of Fit for the Measurement and Structural Model

\begin{tabular}{lcccc}
\hline Goodness of fit measures & $\chi^{2}$ (d.f.) & CFI & RMSEA & SRMR \\
\hline Good model fit threshold & Non-sign & $>0.90$ & $<0.08$ & $<0.08$ \\
CFA model & $602.10(276)$ & 0.95 & 0.058 & 0.06 \\
SEM model & $668.25(284)$ & 0.94 & 0.062 & 0.08 \\
\hline
\end{tabular}


Table 5. Descriptive Statistics for Latent Variables $(N=347)$

\begin{tabular}{|c|c|c|c|c|c|c|c|c|c|c|c|c|c|}
\hline & & Mean & SD & CR & AVE & 1 & 2 & 3 & 4 & 5 & 6 & 7 & 8 \\
\hline 1 & Interpersonal PCV & 3.91 & 2.01 & 0.86 & 0.68 & 0.82 & & & & & & & \\
\hline 2 & Institutional PCV & 3.62 & 1.87 & 0.95 & 0.83 & 0.43 & 0.91 & & & & & & \\
\hline 3 & IUIPC - Control & 5.25 & 1.41 & 0.78 & 0.55 & $0.03^{\# \#}$ & 0.25 & 0.74 & & & & & \\
\hline 4 & IUIPC - Aware & 6.05 & 1.24 & 0.86 & 0.68 & $-0.07^{\# \#}$ & 0.25 & 0.57 & 0.83 & & & & \\
\hline 5 & IUIPC - Collection & 5.51 & 1.44 & 0.87 & 0.68 & 0.18 & 0.44 & 0.41 & 0.47 & 0.83 & & & \\
\hline 6 & Interpersonal Trust & 4.33 & 1.43 & 0.90 & 0.70 & -0.19 & -0.10 & 0.11 & $0.0004 \#$ & -0.17 & 0.84 & & \\
\hline 7 & Institutional Trust & 3.77 & 1.74 & 0.84 & 0.64 & -0.16 & -0.49 & $-0.12^{\#}$ & -0.27 & -0.42 & 0.41 & 0.80 & \\
\hline 8 & Sharing Intention & 4.59 & 1.66 & 0.92 & 0.78 & $-0.08^{\# \#}$ & -0.39 & $-0.06^{\# \#}$ & -0.12 & -0.31 & 0.59 & 0.31 & 0.89 \\
\hline
\end{tabular}

${ }^{\#} p>0.05,{ }^{\#} p>0.10 ; \mathrm{CR}=$ composite reliability; AVE = average variance extracted. The diagonal entries are square roots of AVE.

After the measurement model (CFA) was finalized, we tested the hypothesized model and analyzed the paths between constructs. The fit indices (CFI, RMSEA, SRMR) for the structural model are reported in Table 4. The good model fit ranges are according to Dinev and Hart [9] as well as Hu and Bentler [53]. The results of the fit indices show that the data fits the model properly with a relatively low $\chi^{2}$. All measures of fit are approximately in the acceptable range, indicating an adequate model fit.

The standardized path coefficients of the structural model provide substantial evidence for all the hypothesized relationships (see Figure 2). In particular, interpersonal PCV has significant negative effects on interpersonal trust $(\beta=-0.20, p<0.001)$ and positive effects on institutional PCV $(\beta=0.43, p<$ 0.001 ), thus providing support for both $\mathrm{H} 1$ and $\mathrm{H} 3$. The relationships between institutional PCV and institutional trust $(\beta=-0.41, p<0.001)$ as well as IUIPC $(\beta=0.44, p<0.001)$ are highly significant which indicate the vital role of institutional violation on reducing trust and increasing privacy concern. This provides support for $\mathrm{H} 2$ and $\mathrm{H} 4$. The path between IUIPC and institutional trust is negative and significant ( $\beta=-0.21, p<0.01)$, which supports hypothesis 5 that high information privacy concern will reduce user's trust toward Facebook. Finally, the effects of both interpersonal $(\beta=0.12, p<0.05)$ and institutional $(\beta=0.56, p<0.001)$ trust on sharing intention are positive and significant, hence are consistent with our hypotheses (supporting H6 and H7). In sum, all relationships of the theoretical model are statistically significant (mostly at 0.001 level), indicating that all hypotheses are supported (Figure 2).

Finally, we conduct mediation analyses by Sobel tests [54]. The results suggest that the mediation effect of interpersonal trust between interpersonal PCV and sharing intention is significant $(p<0.05)$. Similarly, the mediation effect of institutional trust between institutional PCV and sharing intention is also significant $(p<0.001)$. Also, the mediation effect of IUIPC between institutional PCV and institutional trust is significant $(p<0.01)$.

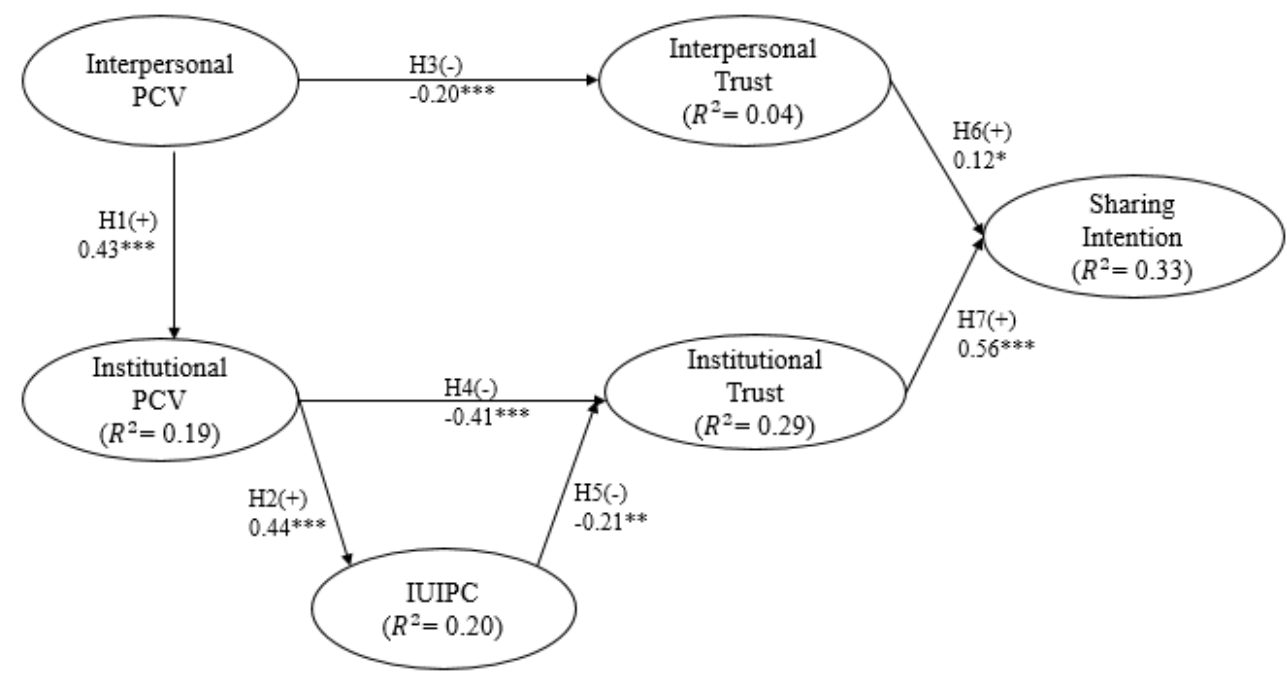

Figure 2. SEM Completely Standardized Path Coefficients. $* p<0.05 ; * * p<0.01 ; * * * p<0.001$. 


\section{Discussion and Conclusion}

Overall, the findings of the study suggest that psychological contract violations (PCVs) with individual users and social network site (SNS) discourage users' sharing intentions by lowering their interpersonal and institutional trust and raising their information privacy concerns towards the site. Moreover, there is a spillover effect of interpersonal PCV towards institutional PCV.

Before discussing the implications of the findings, it is worth acknowledging some limitations of this study. First, our evaluation of the research model is limited to US users on Facebook. Feelings of violations may vary due to cultural differences in different countries, as well as different types of SNSs (e.g., Instagram, LinkedIn). Second, despite the vignette development, we did not categorize the sources of PCV as in Pavlou and Gefen [4] or perceived obligations as in Koh et al. [19]. Such taxonomy would be meaningful to understand which types of violations or failed obligations have stronger effects towards sharing intention. Third, due to the nature of a survey study, we did not include network effects in the model. Choi et al. [31] found that feelings of privacy invasion are stronger for users with low network commonality. For the same action, a user may experience different levels of feelings of violations based on the closeness or the number of common friends with the other user. Fourth, some related constructs were left out from the model for various reasons. Actual behavior was not considered in this paper due to lack of measure for survey studies. We acknowledge that behavioral intention does not always imply actual behavior [55]. Also, IUIPC was used instead of the general privacy concern for contextspecific purposes, even though the latter also includes privacy concern towards individual users. Finally, since we are mainly interested in the effect of PCV towards sharing intention, we did not delve into interrelationships between constructs such as interpersonal and institutional trusts.

Despite its limitations, this paper has a few theoretical implications. The study contributes to the privacy literature on SNS on three fronts. First, this paper offers a framework that explains users' sharing intention on SNS beyond the traditional trust and information privacy concern. The results suggest a fundamental role of psychological contract violation in social media exchange. Second, while generalization of PCV to other parties is typically towards similar entities, such as from one employer to another [33], from one service provider to another [32], and from one online vendor to another [4], we have shown a cross generalization of PCV from an individual to an institution, suggesting the irrationality of over-generalization in terms of PCV may be higher than previously discovered. Third, although psychological contract has previously been applied in e-commerce $[4,8,16-18]$ and IT-outsourcing $[19,20]$, this study offers a meaningful extension from utilitarian contexts to a hedonic environment, where users on SNS are intrinsically motivated [56] to share content in the system as opposed to extrinsic motivations in e-commerce.

For managers, this study has revealed a framework and intricacy in evaluating users' sharing intention on SNS. While an SNS may hold up its end of contract according to legal documents, users may still perceive violations of the psychological contract. In addition, even when the SNS did not violate the psychological contract, violation by another user may incur collateral damage towards the psychological contract between a user and the SNS, and consequently discourages the user from sharing on the site. Therefore, SNS should not only introduce mechanisms to reduce institutional PCVs, but also interpersonal PCVs. For example, since posting with tagging has been shown to have a significant effect towards feelings of privacy invasion [31], SNSs may consider introducing more control to this function in order to reduce interpersonal PCVs as well as generalized feelings of violation towards the SNS. With reduced PCVs, social network sites will be more likely to avoid incidents such as \#DeleteFacebook, thereby retaining the user base.

\section{Acknowledgement}

We would like to thank Dr. David Biros of Oklahoma State University for funding this project and commenting on the manuscript. We also appreciate inputs from Dr. Andy Luse, Dr. Isaac Washburn of Oklahoma State University and Dr. Nan (Peter) Liang from Louisiana State University. Finally, we would like to thank the anonymous reviewers and mini-track chairs for providing thoughtprovoking comments.

\section{References}

[1] A. M. Kaplan and M. Haenlein, "Users of the world, unite! The challenges and opportunities of Social Media," Business horizons, vol. 53, no. 1, pp. 59-68, 2010.

[2] J. A. Obar and A. Oeldorf-Hirsch, "The biggest lie on the internet: Ignoring the privacy policies and terms of service policies of social networking services," 2016.

[3] D. M. Rousseau, "Psychological and implied contracts in organizations," Employee Responsibilities and Rights Journal, vol. 2, no. 2, pp. 121-139, 1989. 
[4] P. A. Pavlou and D. Gefen, "Psychological contract violation in online marketplaces: Antecedents, consequences, and moderating role," Information systems research, vol. 16, no. 4, pp. 372-399, 2005.

[5] S. L. Robinson, "Trust and breach of the psychological contract," Administrative science quarterly, pp. 574-599, 1996.

[6] S. L. Robinson and E. W. Morrison, "The development of psychological contract breach and violation: A longitudinal study," Journal of organizational Behavior, pp. 525-546, 2000.

[7] N. F. Awad and M. S. Krishnan, "The personalization privacy paradox: an empirical evaluation of information transparency and the willingness to be profiled online for personalization," MIS quarterly, pp. 13-28, 2006.

[8] G. Bansal and D. Gefen, "The impact of personal dispositions on information sensitivity, privacy concern and trust in disclosing health information online," Decision support systems, vol. 49, no. 2, pp. 138-150, 2010.

[9] T. Dinev and P. Hart, "An extended privacy calculus model for e-commerce transactions," Information systems research, vol. 17, no. 1, pp. 61-80, 2006.

[10] N. K. Malhotra, S. S. Kim, and J. Agarwal, "Internet users' information privacy concerns (IUIPC): The construct, the scale, and a causal model," Information systems research, vol. 15, no. 4, pp. 336-355, 2004.

[11] C. Dwyer, S. Hiltz, and K. Passerini, "Trust and privacy concern within social networking sites: A comparison of Facebook and MySpace," in AMCIS 2007 proceedings, 2007, p. 339.

[12] J. Fogel and E. Nehmad, "Internet social network communities: Risk taking, trust, and privacy concerns," Computers in human behavior, vol. 25, no. 1, pp. 153-160, 2009.

[13] W. S. Chow and L. S. Chan, "Social network, social trust and shared goals in organizational knowledge sharing," Information \& management, vol. 45, no. 7, pp. 458-465, 2008.

[14] D. Sledgianowski and S. Kulviwat, "Using social network sites: The effects of playfulness, critical mass and trust in a hedonic context," Journal of Computer Information Systems, vol. 49, no. 4, pp. 74-83, 2009.

[15] S. Valenzuela, N. Park, and K. F. Kee, "Is there social capital in a social network site?: Facebook use and college students' life satisfaction, trust, and participation," Journal of computer-mediated communication, vol. 14, no. 4, pp. 875-901, 2009.

[16] C.-M. Chiu, H.-Y. Huang, and C.-H. Yen, "Antecedents of trust in online auctions," Electronic Commerce Research and Applications, vol. 9, no. 2, pp. 148-159, 2010.

[17] A. F. Salam, L. Iyer, P. Palvia, and R. Singh, "Trust in e-commerce," Communications of the ACM, vol. 48, no. 2, pp. 72-77, 2005.

[18] B. Xiao and I. Benbasat, "Product-related deception in e-commerce: a theoretical perspective," Mis Quarterly, vol. 35, no. 1, pp. 169-196, 2011.

[19] C. Koh, S. Ang, and D. W. Straub, "IT outsourcing success: A psychological contract perspective," Information systems research, vol. 15, no. 4, pp. 356-373, 2004.
[20] R. Sabherwal, "The role of trust in outsourced IS development projects," Communications of the ACM, vol. 42, no. 2, pp. 80-86, 1999.

[21] Z. R. Steelman, B. I. Hammer, and M. Limayem, "Data Collection in the Digital Age: Innovative Alterantives to Student Samples," MIS Quarterly, vol. 38, no. 2, pp. 355378, 2014.

[22] Statista. (2018). Most popular social networks worldwide as of April 2018, ranked by number of active users (in millions). Available: https://www.statista.com/statistics/272014/global-socialnetworks-ranked-by-number-of-users/

[23] C. Argyris, "Understanding organizational behavior," 1960.

[24] K. E. Weick, The social psychology of organizing. 1979.

[25] O. Hart and J. Moore, "Foundations of incomplete contracts," The Review of Economic Studies, vol. 66, no. 1, pp. 115-138, 1999.

[26] D. Rousseau, Psychological contracts in organizations: Understanding written and unwritten agreements. Sage Publications, 1995.

[27] E. W. Morrison and S. L. Robinson, "When employees feel betrayed: A model of how psychological contract violation develops," Academy of management Review, vol. 22, no. 1, pp. 226-256, 1997.

[28] S. L. Robinson and D. M. Rousseau, "Violating the psychological contract: Not the exception but the norm," Journal of organizational behavior, vol. 15, no. 3, pp. 245259, 1994.

[29] Facebook. (2018). Terms of Service. Available: https://www.facebook.com/terms.php

[30] Z. Kleinman, "Facebook: Cambridge Analytica warning sent to users," in $B B C$, ed, 2018.

[31] B. C. Choi, Z. Jiang, B. Xiao, and S. S. Kim, "Embarrassing exposures in online social networks: An integrated perspective of privacy invasion and relationship bonding," Information Systems Research, vol. 26, no. 4, pp. 675-694, 2015.

[32] V. S. Folkes and V. M. Patrick, "The positivity effect in perceptions of services: seen one, seen them all?," Journal of Consumer Research, vol. 30, no. 1, pp. 125-137, 2003.

[33] S. D. Pugh, D. P. Skarlicki, and B. S. Passell, "After the fall: Layoff victims' trust and cynicism in re-employment," Journal of Occupational and Organizational Psychology, vol. 76, no. 2, pp. 201-212, 2003.

[34] A. J. Campbell, "Relationship marketing in consumer markets: A comparison of managerial and consumer attitudes about information privacy," Journal of Interactive marketing, vol. 11, no. 3, pp. 44-57, 1997.

[35] G. C. Homans, Social behavior: Its elementary forms. 1974.

[36] S. C. Chen and G. S. Dhillon, "Interpreting dimensions of consumer trust in e-commerce," Information Technology and Management, vol. 4, no. 2-3, pp. 303-318, 2003.

[37] D. Gefen, "E-commerce: the role of familiarity and trust," Omega, vol. 28, no. 6, pp. 725-737, 2000.

[38] D. J. Kim, Y. I. Song, S. B. Braynov, and H. R. Rao, "A multidimensional trust formation model in B-to-C ecommerce: a conceptual framework and content analyses of 
academia/practitioner perspectives," Decision support systems, vol. 40, no. 2, pp. 143-165, 2005.

[39] D. H. McKnight, V. Choudhury, and C. Kacmar, "Developing and validating trust measures for e-commerce: An integrative typology," Information systems research, vol. 13, no. 3, pp. 334-359, 2002.

[40] N. Luhmann, Trust and power. 1979 (John Willey \& Sons). 1979.

[41] D. M. Rousseau, S. B. Sitkin, R. S. Burt, and C. Camerer, "Not so different after all: A cross-discipline view of trust," Academy of management review, vol. 23, no. 3, pp. 393-404, 1998.

[42] A. Zaheer, B. McEvily, and V. Perrone, "Does trust matter? Exploring the effects of interorganizational and interpersonal trust on performance," Organization science, vol. 9, no. 2, pp. 141-159, 1998.

[43] D. Gefen, P. Pavlou, I. Benbasat, H. McKnight, K. Stewart, and D. Straub, "ICIS panel summary: should institutional trust matter in information systems research?," Communications of the Association for Information Systems, vol. 17, no. 1, p. 9, 2006.

[44] S. L. Robinson and E. W. Morrison, "Organizational citizenship behavior: A psychological contract perspective," Journal of Organizational Behavior, vol. 16, no. 3, pp. 289298, 1995.

[45] C. S. Lee and L. Ma, "News sharing in social media: The effect of gratifications and prior experience," Computers in human behavior, vol. 28, no. 2, pp. 331-339, 2012.

[46] D. Gefen, E. Karahanna, and D. W. Straub, "Trust and TAM in online shopping: An integrated model," MIS quarterly, vol. 27, no. 1, pp. 51-90, 2003.

[47] K. Yurieff. (2017). Facebook hits 2 billion monthly users. Available:

http://money.cnn.com/2017/06/27/technology/facebook-2billion-users/index.html

[48] M. Buhrmester, T. Kwang, and S. D. Gosling, "Amazon's Mechanical Turk: A new source of inexpensive, yet high-quality, data?," Perspectives on psychological science, vol. 6, no. 1, pp. 3-5, 2011.

[49] J. C. Anderson and D. W. Gerbing, "Structural equation modeling in practice: A review and recommended two-step approach," Psychological bulletin, vol. 103, no. 3, p. 411, 1988.

[50] R. P. Bagozzi and Y. Yi, "On the evaluation of structural equation models," Journal of the academy of marketing science, vol. 16, no. 1, pp. 74-94, 1988.

[51] C. Fornell and D. F. Larcker, "Evaluating structural equation models with unobservable variables and measurement error," Journal of marketing research, pp. 3950, 1981.

[52] W. W. Chin, A. Gopal, and W. D. Salisbury, "Advancing the theory of adaptive structuration: The development of a scale to measure faithfulness of appropriation," Information systems research, vol. 8, no. 4, pp. 342-367, 1997.

[53] L. t. Hu and P. M. Bentler, "Cutoff criteria for fit indexes in covariance structure analysis: Conventional criteria versus new alternatives," Structural equation modeling: a multidisciplinary journal, vol. 6 , no. 1, pp. 1$55,1999$.
[54] M. E. Sobel, "Asymptotic confidence intervals for indirect effects in structural equation models," Sociological methodology, vol. 13, pp. 290-312, 1982.

[55] I. Ajzen, "From intentions to actions: A theory of planned behavior," in Action control: Springer, 1985, pp. 1139.

[56] H. Van der Heijden, "User acceptance of hedonic information systems," MIS quarterly, pp. 695-704, 2004. 